\title{
O lugar da Educação Física: estudo elaborado a partir da realidade da Escola Municipal GEO Juan Antonio Samaranch
}

The place of Physical Education: a study based on the reality of the GEO Juan Antonio Samaranch Municipal School

El lugar de la Educación Física: un estudio a partir de la realidad de la Escuela Municipal GEO Juan Antonio Samaranch

Carlos Eduardo Rafael de Andrade Ferrari ORCID: https://orcid.org/0000-0001-8671-7448 Universidade do Porto, Portugal E-mail: ceraferrari@yahoo.com.br

Rafael Mocarzel

ORCID: https://orcid.org/0000-0001-9480-826X Universidade Federal do Rio de Janeiro, Brasil Universidade de Vassouras, Brasil Universidade do Porto, Portugal E-mail: professormocarzel@gmail.com

Amândio Braga dos Santos Graça ORCID: https://orcid.org/0000-0003-1539-4201 Universidade do Porto, Portugal E-mail: agraca@fade.up.pt

Roberto Ferreira dos Santos ORCID: https://orcid.org/0000-0003-0168-5286 Universidade do Porto, Portugal Universidade Salgado de Oliveira, Brasil E-mail: rob.fersantos1949@gmail.com

\begin{abstract}
Resumo
Introdução: O artigo objetiva analisar o lugar da Educação Física a partir da realidade da Escola Municipal GEO Juan Antonio Samaranch. O estudo sumariza o cenário escolar vigente, nomeadamente a valia da Instituição Escola no contexto fluminense, como panorama de uma reflexão mais abrangente. Método: A investigação caracteriza-se por uma pesquisa qualitativa de cunho sociocultural. O estudo ocorreu no período compreendido entre os meses de fevereiro e novembro de 2018. A pesquisa utilizou a técnica de Triangulação das informações e a Abordagem multimétodos. A matriz analítica da investigação compõe as lentes teóricas dos sociólogos Norbert Elias e Pierre Bourdieu, conjuntamente com a interpretação indutiva que aflora da Análise Crítica do Discurso. Resultados e discussão: Nesse enquadramento, observa-se que o capital simbólico do Esporte, da Educação Física, antes compreendido como diferenciação social positiva, perdeu espaço na agenda dos homens públicos brasileiros com o término dos megaeventos esportivos. Nesta esteira de pensamento, há fortes indícios que sugestionam que a unidade escolar em voga é apenas o apêndice desse eixo de tensões; o reflexo microssocial do "Negado" dos megaeventos esportivos. Considerações finais: Nessa disposição, identifica-se que a unidade averiguada é uma escola que procura blindar suas práticas enquanto enjeita a anticultura e as forças motrizes que hodiernamente desestabilizam a formação integral dos alunos, principalmente daqueles cuja escola é o único espaço de aprendizagem pedagogicamente orientada. No entanto, o GEO Juan Antonio Samaranch ainda é uma exceção; não retrata o cenário caótico da maioria das escolas municipais do Rio de Janeiro.
\end{abstract}

Palavras-chave: Escola pública; Esporte educacional; Megaeventos esportivos; Legado olímpico; Discurso oficial; Manifestação oficiosa; Fisiologismo político.

\begin{abstract}
Introduction: This article aims to analyze the place of Physical Education from GEO Juan Antonio Samaranch Municipal School's reality. The study summarizes the current school scenario, namely the value of the School Institution in the context of Rio de Janeiro, as an overview for a broader reflection. Method: The investigation is characterized by a qualitative research of sociocultural nature. The study occurred in the period between February and November of 2018. The research used the Information Triangulation technique and Multimethod Approach. The analytical matrix of the investigation composes theoretical lenses of the sociologists Norbert Elias and Pierre Bourdieu, along with the inductive interpretation that emerges from the Critical Discourse Analysis. Results and
\end{abstract}


discussion: In this framework, it is observed that the symbolic Sport capital, of Physical Education, previously understood as a positive social differentiation, lost space in Brazilian public agenda with the end of sports megaevents. In this wake of thoughts, there are strong indications that suggest that the school unit, in vogue, is just the appendix of this axis of tensions; the microsocial reflex of the "Denied" of sports mega-events. Final considerations: In this disposition, it is identified that the investigated unit is a school that seeks to shield its practices while rejecting the anti-culture and the driving forces that currently destabilize the integral education of students, especially those whose school is the only pedagogically oriented learning space. However, GEO Juan Antonio Samaranch is still an exception; it does not portray the chaotic scenario of most municipal schools in Rio de Janeiro.

Keywords: Public school; Educational sport; Sports mega-events; Olympic legacy; Official speech; Unofficial manifestation; Political cronyism.

\begin{abstract}
Resumen
Introducción: El artículo tiene como objetivo analizar el lugar de la Educación Física desde la realidad de la Escuela Municipal GEO Juan Antonio Samaranch. El estudio resume el escenario escolar actual, es decir, el valor de la Institución Escolar en el contexto de Río de Janeiro, como panorama para una reflexión más amplia. Método: La investigación se caracteriza por una investigación cualitativa de carácter sociocultural. El estudio se llevó a cabo entre febrero y noviembre de 2018. La investigación utilizó la técnica de triangulación de la información y el enfoque multimétodo. La matriz analítica de la investigación compone las lentes teóricas de los sociólogos Norbert Elias y Pierre Bourdieu, junto con la interpretación inductiva que surge del Análisis Crítico del Discurso. Resultados y discusión: En este contexto, se observa que el capital simbólico del Deporte, la Educación Física, antes entendida como diferenciación social positiva, perdió espacio en la agenda de los hombres públicos brasileños con el fin de los megaeventos deportivos. En esta línea de pensamiento, hay fuertes indicios que sugieren que la unidad escolar en boga es solo el apéndice de este eje de tensiones; el reflejo microsocial del "Negado" de los megaeventos deportivos. Consideraciones finales: En esta disposición, se identifica que la unidad investigada es una escuela que busca blindar sus prácticas mientras rechaza la anticultura y los motores que actualmente desestabilizan la educación integral de los estudiantes, especialmente aquellos cuya escuela es la única pedagógicamente. Espacio de aprendizaje orientado. Sin embargo, GEO Juan Antonio Samaranch sigue siendo una excepción; no retrata el escenario caótico de la mayoría de las escuelas municipales de Río de Janeiro.
\end{abstract}

Palabras clave: Escuela pública; Deporte educativo; megaeventos deportivos; Legado olímpico; Discurso oficial; Manifestación no oficial; Fisiología política.

\title{
1. Introdução
}

O presente artigo objetiva analisar o lugar da Educação Física (EF) a partir da realidade da Escola Municipal GEO Juan Antonio Samaranch. Trata-se de um texto adaptado da tese de doutoramento "O lugar da Educação Física na Escola Cultural. Estudo elaborado a partir da realidade de duas escolas sui generis do Porto e do Rio de Janeiro", que visa a efetivamente abordar os <<pormenores reveladores >> e o <<contexto sociocultural >> da primeira escola vocacionada para 0 esporte do Brasil. Posto em outros termos, isso equivale a dizer que o artigo pretende repercutir o reflexo microssocial do "Negado" dos megaeventos esportivos, visto que a escola em apreço, neste diapasão, seria apenas o apêndice desse eixo de tensões (Trajan et al., 2013; Ferrari, 2020).

Nesse enquadramento, o artigo intenta sumarizar o cenário escolar vigente, nomeadamente a valia da Instituição Escola no contexto fluminense, como panorama de uma reflexão mais abrangente. Isso se revela significativo, pois transcende as relações especificamente escolares, sob a justificativa mais que emergente da preservação da vida dos que estão expostos à exclusão e à vulnerabilidade social. A intenção é, justamente, compreender por intermédio dos excertos e das demais fontes da informação os aspectos que porventura envolvem o lugar da Educação Física no ambiente escolástico. "Afinal, todo chão da escola é (deveria ser) o lugar da Educação Física, já que toda escola - independentemente do argumento - é constituída por corpos-mentes em movimento!” (Ferrari, 2020, p. 259, grifo do autor).

Não obstante, como se vê, no tocante à literatura especializada brasileira, a legitimidade, a autenticidade da Educação Física Escolar, como doutrina de uma escola que se assume como instituição social no âmbito de uma sociedade democrática, é algo que requer lutas e intervenções em variadas dimensões. Elenor Kunz (1995), sob esse prisma, questiona: “[...] como e com que objetivos os conhecimentos científicos (teorias) produzidos para a área da Educação Física se tornam conteúdos úteis às práticas pedagógicas da Educação Física Escolar?” (p. 48, grifo do autor). Tarcísio Vago (1996), na esteira desse debate, 
indaga: "É impossível a escolarização do esporte, isto é, a produção de um "esporte da escola", que seja uma prática da cultura escolar, com seus códigos próprios?” (p. 9, grifo do autor).

No que tange às instalações e os equipamentos esportivos, Alex Almeida (2012), debruçado sobre essas questões, denuncia que a Educação Física, como disciplina curricular obrigatória, "tem sido negligenciada nas escolas brasileiras, especialmente as públicas, pois, entre outras limitações, de cada cinco (05) escolas apenas uma (01) tem equipamento para a prática de atividades desportivas." (p. 55). Carlos Silva (2013), lançando mão de dados do fórum do jornal Lance, expõe que um número vultoso de colégios públicos do município do Rio de Janeiro não possui espaços destinados à prática da Educação Física. Ou seja, não é de hoje que o professor de escola pública, em especial o professor de Educação Física, sofre com a desvalorização e a desestruturação do ambiente laboral (Barbosa, 2011; Valladão et al., 2013).

Outro fato que o artigo expõe e que sugere a obscuridade do ambiente laboral, particularmente da capital fluminense, é a questão da violência, fenômeno que acomete um número considerável de escolas municipais, comumente situadas em áreas conflagradas, dificultando a relação e o quotidiano dos agentes sociais em equivalência (Santos \& Silva, 2020). A Diretoria de Análise de Políticas Públicas da Fundação Getúlio Vargas, com colaboração do aplicativo Fogo Cruzado, divulgou um estudo da situação da violência armada na cidade do Rio de Janeiro. Segundo os envolvidos na pesquisa, a exposição rotineira à violência pode prejudicar o processo ensino-aprendizagem. Quer dizer, "quanto mais próxima é a violência, e quanto mais novo é o indivíduo, maiores são os efeitos da exposição à violência." (FGV, 2017, p. 4).

Em razão disso, pode-se, por conseguinte, anunciar, nessa fase introdutória do debate, que a Escola Municipal GEO Juan Antonio Samaranch quebra uma sucessão de paradigmas. Tendo em vista que é uma das poucas unidades escolares da Secretaria Municipal de Educação do Rio de Janeiro (SME/RJ) a alcançar desempenho satisfatório estando localizada numa região dominada por facções de narcotraficantes. Desta forma, as medalhas conquistadas na OBMEP 2018 - na 14. ${ }^{\text {a } ~ O l i m p i ́ a d a ~}$ Brasileira de Matemática das Escolas Públicas + Privadas - ganham destaque, já que são premiações idealizadas no meio do fogo cruzado, isto é, sob o regime do medo (Alves \& Evanson, 2013; Mattos, 2014; Silva \& Silva, 2014; Barbosa, 2015; Silva, 2017; Ferrari, 2020).

Assim, visto que a Escola Municipal GEO Juan Antonio Samaranch, atual Escola Municipal Olímpica Carioca Juan Antonio Samaranch, é uma das unidades escolares da SME/RJ que, na figura dos seus agentes, procura implementar suas práticas pedagógicas à luz da Educação Física e as suas dimensões, o estudo justifica-se e mostra-se relevante. Sobretudo no plano da pesquisa de cariz qualitativo, quer em relação à literacia científica da área da Educação Física, quer em relação à reestruturação paradigmática da intervenção em Educação Física quanto à ação educativa da escola em especial, dado que, na ocasião dos preparativos dos megaeventos esportivos, a unidade escolar em voga era a menina-dos-olhos dos homens públicos brasileiros (Ferrari, 2020).

\section{Metodologia}

Os tópicos abaixo relacionados visam a salientar os pontos-chave do método, no qual compor a imaginação metodológica torna-se estratégia no que tange à optimização das informações. A pesquisa pode ser descrita como um estudo de caso, com um viés exploratório, considerando a pretensão de investigar o lugar da EF a partir da realidade da EM GEO Juan Antonio Samaranch. Empregaram-se no estudo diferentes perspectivas na recolha de dados, as quais posteriormente foram alvo de uma análise indutiva. Os investigadores, à vista disso, estavam em busca de uma abordagem holística (fenomenológica) que englobasse a abordagem multimétodos e o pluralismo metodológico que delimitou o estudo (Minayo, 1994; Flick, 2004; Yin, 2005). 


\subsection{Tipo de estudo}

O estudo caracteriza-se por uma pesquisa qualitativa de cunho sociocultural, tendo em vista que a adoção do método, segundo Uwe Flick (2004), viabiliza a interação, a aproximação ao locus, promovendo, assim, a flexibilidade, a abertura e a adaptabilidade metodológica necessária em estudos dessa natureza. Uwe Flick (2004), nesse sentido, dá a entender que a necessidade de se elucidar questões subjetivas é que levou o campo científico, os cientistas sociais, a adotarem os princípios qualitativos. Maria Minayo (1994, p. 21), seguindo uma linha de raciocínio similar, declara: "A pesquisa qualitativa responde a questões muito particulares. Ela se preocupa, nas ciências sociais, com um nível de realidade que não pode ser quantificado", que é o caso do estudo em voga.

\subsection{Contexto, participantes e procedimentos da pesquisa}

A pesquisa foi realizada na EM GEO Juan Antonio Samaranch, unidade escolar que faz parte da E/SUBE/ $1{ }^{\mathrm{a} C R E}$ da Rede Pública do Sistema Municipal de Ensino da Cidade do Rio de Janeiro. O estudo ocorreu no período compreendido entre os meses de fevereiro e novembro de 2018, obedecendo ao calendário escolar vigente e às datas pré-estabelecidas pela instituição acima mencionada. Nesse contexto, constam como investigados diretos: 2 agentes diretivos; 3 docentes; 5 docentes de Educação Física; 20 discentes. Como procedimentos da pesquisa, os investigados indiretos, a fim de informação, referem-se aos sujeitos pesquisados que fizeram parte do contexto estudado, mas que não participaram diretamente da averiguação.

\subsection{Instrumentos de coleta de dados}

O estudo utilizou a técnica de "Triangulação das informações" (Triviños, 1987). A "Observação participante" mostrou-se pertinente, pois permitiu esmiuçar a práxis da unidade escolar, resultando na compreensão da identidade social dos sujeitos averiguados (Pereira, 2013). A "Entrevista semiestruturada" 1,2 mapeou as questões abertas, permitindo, como advoga Airton Negrine (1999), "explorações não previstas, oferecendo liberdade ao entrevistado para dissertar sobre o tema ou abordar aspectos que sejam relevantes sobre o que pensa." (p. 74). Já a "Entrevista de grupo focal" 3, 4 , à luz da imaginação metodológica de Bernardete Gatti (2005), partiu da necessidade de extrapolar o campo social da Educação Física, a fim de possibilitar aos investigadores a compreensão, por exemplo, do ponto de vista dos docentes das disciplinas ditas convencionais (Matemática, Português, etc.).

\subsection{Análise de dados}

A matriz analítica da investigação compõe as lentes teóricas dos sociólogos Norbert Elias e Pierre Bourdieu, conjuntamente com a interpretação indutiva que aflora da Análise Crítica do Discurso (Elias, 1939a; Elias, 1939b; Elias, 1999; Bourdieu, 2007a; Bourdieu, 2007b; Bourdieu, 2012; Fairclough \& Melo, 2012). Isso, do ponto de vista pragmático, resulta numa abordagem predisposta a dialogar com o contexto micro (linguagem visual, linguagem corporal dos investigados), sem se desvincular da conjuntura macro (lentes teóricas dos sociólogos). Assim, os pesquisadores analisaram o objeto de estudo considerando três configurações centrais: i) o lugar da EF na sociedade (perspectiva de nível macro); ii) o lugar da EF na EM

\footnotetext{
${ }^{1}$ Entrevista semiestruturada: 1 diretor e 1 diretor-adjunto da EM GEO Juan Antonio Samaranch. Os agentes diretivos, como os demais investigados diretos, assinaram o Termo de Consentimento Livre e Esclarecido e colaboraram de modo voluntário no tocante ao desenvolvimento do estudo.

2 Entrevista semiestruturada: 1 docente de EF do segundo segmento (6..$^{\circ}$ ano), 1 docente de EF do segundo segmento (7..$^{\circ}$ 8. ${ }^{\circ}$ e $9 .^{\circ}$ ano) e 3 docentes/treinadores do segundo segmento $\left(6 .^{\circ}, 7 .^{\circ}, 8 .^{\circ}\right.$ e $9 .^{\circ}$ ano) do ensino fundamental. Os investigados diretos foram predeterminados pela direção da escola.

${ }^{3}$ Entrevista de grupo focal: 1 docente de Português do segundo segmento (6. ${ }^{\circ}$ ano), 1 docente de Arte do segundo segmento (7., $8 .^{\circ}$ e $9 .^{\circ}$ ano) e 1 docente de Matemática do segundo segmento $\left(7 .^{\circ}, 8 .^{\circ}\right.$ e $9 .^{\circ}$ ano) do ensino fundamental. Os investigados diretos foram predeterminados pela direção da escola.

${ }^{4}$ Entrevista de grupo focal: 5 discentes do segundo segmento ( $6 .^{\circ}$ ano), 5 discentes do segundo segmento ( $7 .^{\circ}$ ano), 5 discentes do segundo segmento ( $8 .^{\circ}$ ano) e 5 discentes do segundo segmento ( $9 .^{\circ}$ ano) do ensino fundamental. A escolha dos discentes ingressantes na participação do estudo ocorreu a partir dos seguintes perfis: i) disponibilidade motora; ii) indisponibilidade motora; iii) disciplinado; iv) indisciplinado; v) morador local.
} 
GEO Juan Antonio Samaranch (perspectiva de nível meso); iii) o lugar da EF no imaginário dos investigados em estudo (perspectiva de nível micro).

\subsection{Procedimentos éticos}

O estudo passou pelo crivo da Comissão de Ética da Faculdade de Desporto, colegiado autônomo que visa à integridade, à honestidade e à qualidade ética na atividade da Universidade do Porto e dos seus pares. (Processo CEFADE 09.2017). Nessa condição, a Equipe Técnica da E/SUBE/CED/GEF - Educação Física, órgão subordinado à Secretaria Municipal de Educação, Esportes e Lazer e à Subsecretaria de Ensino da Coordenadoria de Educação, autorizou a realização da pesquisa. (Processo 07/002.356/2017). Deste modo, como meio de aclarar os pormenores inerentes ao estudo, os investigadores disponibilizaram o Termo de Consentimento Livre e Esclarecido, documento que visou a explicitar que se tratava de uma pesquisa científica, em que a participação não era obrigatória, podendo o investigado retirar-se do estudo a qualquer momento e que o anonimato seria garantido.

\section{Resultados e Discussão}

De maneira geral, deve-se frisar que os depoimentos, os dados, as notas de campo e os registros apontados durante a observação participante, permitiram perspectivar o passado recente da EM GEO Juan Antonio Samaranch. Nesse processo, a concepção metodológica, alinhada com a matriz analítica, revela-se pertinente, já que possibilitou explorar uma "configuração" pregressa (Elias, 1999). Consequentemente, caso o objetivo do estudo fosse analisar o passado recente da escola por si só, possivelmente os investigadores constatariam que desde a sua concepção algo de inusitado pairava no ar. No entanto, decidiuse por ampliar o campo de reflexão e averiguar nos tópicos seguintes tanto o contexto pregresso quanto o período hodierno da primeira escola vocacionada para o esporte do Brasil.

O passado recente da EM GEO Juan Antonio Samaranch: recorte 2012-2017Em verdade, a EM GEO Juan Antonio Samaranch é uma ilha! Geograficamente situada entre o conflagrado bairro do Rio Comprido e o pitoresco bairro de Santa Teresa, destoa da paisagem social no momento em que apresenta para a sociedade civil fluminense um paradigma educacional sui generis. Implantado - no início do ano letivo de 2012 - com a pretensão de ser um dos legados dos Jogos Olímpicos Rio 2016, a unidade escolar em apreço, na figura dos seus agentes, luta para preservar a máxima do "Aluno - Atleta - Cidadão", diferenciação que, ainda hoje, incentiva crianças e jovens a atravessarem a cidade em busca da oportunidade de ingressar numa escola vocacionada para o esporte, de horário integral, com fins na excelência acadêmica e esportiva (Mattos, 2014; Silva \& Silva, 2014).

Além disso, é preciso destacar que a EM GEO Juan Antonio Samaranch possui uma infraestrutura considerável, composta por: 4 pavimentos; guarita de segurança; pista de Atletismo; campo de Futebol; sala de secretaria; sala de diretoria; almoxarifado; sala de professores; sala de primeiros socorros; sala informatizada; laboratório de Ciências; sala de leitura; biblioteca; piscina; banheiros na área interna do prédio; banheiros na área externa ao prédio; refeitório; despensa; auditório; sala de Tênis de Mesa; sala de Judô; sala de Xadrez; academia; quadra de Badminton; quadra de esporte coberta; 19 salas de aula; elevador; dependências apropriadas para deficientes e ampla área verde. Estrutura essa que destoa inclusive do espaço físico esportivo dos demais Ginásios Experimentais Olímpicos (Almeida, 2012; Silva, 2013).

Diante desse quadro, para uma melhor compreensão dessas questões, faz-se necessário abrir um parêntese e apresentar excertos que repercutem e ajudam a analisar o espaço físico esportivo da EM GEO Juan Antonio Samaranch, como um dos símbolos que efetivamente caracterizam o cariz sui generis da unidade escolar em análise, sobretudo o conjunto de 
características (propriedades) distintivas que acaba por influenciar positivamente a rotina daqueles que por lá estiveram e ainda estão - os sujeitos pesquisados de forma direta e/ou indireta (Bourdieu, 2007b; Bourdieu, 2012).

Capital simbólico:

- "Ela é uma escola que tem esporte, eu não preciso transportar minha filha de uma localidade pra outra, é menos um gasto. Se você bota em outra escola, que não é integral, você tem os esportes que é pago, é longe, não pode levar, aqui não, tem tudo aqui dentro, tudo que você proporciona para o seu filho; aqui existe. É pão, esporte. É tudo. Eu só tenho a agradecer." (Silva, 2014, p. 55).

Capital cultural:

- "Meu filho hoje tem apenas 13 anos, mas eu posso afirmar que esta escola, Juan Antonio Samaranch, marcou para sempre sua vida. Aqui ele se desenvolveu em todos os aspectos, ficou apaixonado pelos esportes e desenvolveu dentro de si um forte espírito de vencedor, que com certeza o acompanhará pelo decorrer de sua vida. Confesso que no início tive um pouco de dúvida em relação a este trabalho, pois era tudo muito novo e em grande quantidade e qualidade, além da distância da residência. Porém ao longo do ano comecei a perceber o quanto ele estava apaixonado pela escola e principalmente, o quanto ele sentia-se bem em estar aqui." (Zeferino, 2014, p. 170-171).

Diferenciação social positiva:

- "[...]. Só tenho a agradecer a todos que participam do desenvolvimento do GEO, da formação dos atletas, do caráter, do conhecimento (aprendizado). Amo essa escola! Costumo dizer que eu queria uma vaga para mim. Rs. Meus familiares não acreditam que essa escola realmente existe, agora todos já sabem através das fotos, vídeos, porque é difícil acreditar que uma escola do município seja "completa." Enfim, torço pela escola, por vocês, por todos nós. Que venham os desafios, porque a vitória já é nossa!” (Zeferino, 2014, p. 174, grifo do autor).

Fechando o parêntese e voltando à discussão, observa-se que é uma proposta de Escola que, desde a sua concepção, não retrata o cenário caótico da maioria das escolas municipais do Rio de Janeiro, possuindo um currículo, uma infraestrutura, uma perspectiva de Escola totalmente diferenciada das demais unidades escolares da SME/RJ. Nessa lógica, o teste de seleção dos alunos 5; o horário integral; a educação para a cidadania; o estudo dirigido; a entrevista de seleção dos professores; a proatividade docente; o regime de quarenta horas; o esporte na grade curricular; a figura do treinador; as cinco refeições diárias; os cinco tempos semanais de Inglês, tudo isso deu não só um projeto político pedagógico à Escola Municipal GEO Juan Antonio Samaranch, mas iniciou um modelo educacional inovador (Silva \& Silva, 2014; Mattos, 2014; Barbosa, 2015; Silva, 2017).

À época, segundo o relato de professores, a visitação de políticos, de atletas olímpicos, de celebridades era constante ${ }^{6}$. A Rede Globo, a maior rede de televisão do país, exibia o treino dos alunos em horário nobre. A captação de recursos não era um problema. A oferta de ônibus, por exemplo, era abundante; a remessa de material era expressiva; a manutenção das áreas acadêmicas e esportivas era frequente. Os agentes diretivos, à luz da investigação, tinham carta branca da SME/RJ. A

\footnotetext{
${ }^{5}$ A fim de informação: o processo de seleção e classificação dos alunos baseia-se fundamentalmente em dois critérios. O primeiro, sob responsabilidade da esfera esportiva, visa a avaliar a aptidão física e a disponibilidade motora (0-60 valores). Enquanto o segundo, sob responsabilidade da área acadêmica, visa a avaliar a capacidade de leitura, escrita e articulação de ideias do aspirante a <<Aluno-GEO〉> ( $0-40$ valores). As crianças e os jovens que eventualmente não são agraciados pelo projeto (considerados inaptos) são alocados em uma unidade escolar convencional conforme os critérios estipulados pela SME/RJ (Notas de campo).

${ }^{6}$ A fim de informação: no período prévio aos megaeventos esportivos, a polícia - o braço armado do Estado - instalou Unidades de Polícia Pacificadora em áreas conflagradas da cidade. Uma política de segurança implantada pelo governo em meados de 2008 , em conjunto com a esfera municipal e federal do poder público, já que o objetivo do projeto de pacificação (ocupação) das favelas era, supostamente, estabelecer um plano de segurança na intenção dos Jogos Mundiais Militares de 2011; da Copa das Confederações da Federação Internacional de Futebol Associado (FIFA) de 2013; da Copa do Mundo FIFA de 2014; dos Jogos Olímpicos e Paralímpicos Rio 2016. Ou seja, uma política de segurança sazonal que diminuiu consideravelmente a sensação de insegurança na altura dos megaeventos, gerando maior acessibilidade às regiões antes dominadas pelo poder bélico dos narcotraficantes - que é o caso da região em voga e/ou grupos paramilitares (Ferrari, 2014).
} 
requisição de professores, independentemente da Coordenadoria Regional de Educação à qual o docente estivesse vinculado, era autorizada; a troca, a substituição do corpo técnico-administrativo, era permitida (Silva \& Silva, 2014; Mattos, 2014; Barbosa, 2015; Silva, 2017).

Nesse caso, o emprego da entrevista semiestruturada manifestou-se extremamente significativo, dado que propiciou destrinchar o período pregresso da unidade em estudo e, com efeito, constatar que se tratava de um projeto audacioso, cirurgicamente arquitetado e com exigências que ultrapassavam por demais as questões escolares. No bojo desse debate, vale registrar que o então prefeito entregou as chaves da cidade para as mascotes dos Jogos Olímpicos Rio 2016 nas dependências da escola. Nas palavras de um dos pesquisados diretos: - "O projeto, o GEO, é filho de pais riquíssimos, milionários. O GEO nasce no contexto do Brasil pré grandes eventos, pré-copa, pré-olimpíada. O foguete, àquela altura, tinha que decolar: os recursos apareciam de todos os lados. [...]. (Agente diretivo, GEO. Un. Santa Teresa - Entrevista semiestruturada).

Por tudo isso, não seria heresia repercutir que de fato os recursos apareciam de todos os lados. Mas, independentemente do capital, coube ao corpo docente transformar a realidade dos discentes (Mattos, 2014). Dessa maneira, a atitude dos professores de EF que subiram o Morro da Mineira ${ }^{7}$ à procura do aluno faltoso; a história das professoras que adotaram alunos em situação de abandono parental; o compromisso da professora que foi para jogo com pontos de cirurgia cesariana, tudo isso revelou não só a faceta do profissional extremamente compromissado, assim como o engajamento capaz de contagiar o corpo discente, o corpo técnico-administrativo, pais e responsáveis, a ponto de a comunidade escolar não medir esforços quanto à efetividade do projeto.

Concomitantemente e em consequência disso, os números superaram todos os prognósticos. A rivalidade das facções criminosas, algo comum no dia a dia dos jovens de periferia, sucumbia diante das oportunidades educacionais. Indubitavelmente, a glamourização do crime organizado, a "eficácia simbólica" do Comando Vermelho; do Terceiro Comando; do Terceiro Comando Puro ${ }^{8}$, esbarrava nos princípios esportivos que contribuíam para uma decisiva transformação social destes discentes, desencadeando alterações em valores individuais que incluíam conforme os pesquisados: dedicação; entrega; empenho; seriedade; comprometimento; engajamento e resiliência (Bourdieu, 2012; Silva \& Silva, 2014; Mattos, 2014; Barbosa, 2015; Silva, 2017).

Em termos objetivos, as vitórias esportivas vieram como já era de se esperar. Entretanto, o que realmente surpreendeu foi o desempenho acadêmico dos discentes. Nessa conformidade, vê-se por aí que o aluno de escola pública, oriundo de comunidade conflagrada, pode, sim, ascender academicamente. Sob esse enfoque, precisa-se sublinhar, ainda, que o Intercolegial 9 é uma competição que contempla "múltiplas inteligências", tendo o Xadrez como uma das modalidades mais acirradas. Portanto, o aluno de escola pública, oriundo de comunidade conflagrada, pode, se esse for o intento do projeto, ascender até mesmo no campo da inteligência "espacial" e/ou "lógica matemática" (Gardner, 1983; Silva \& Silva, 2014; Mattos, 2014; Barbosa, 2015; Silva, 2017).

Assumir isso é reconhecer, nessa fase intermediária do debate, que o "capital cultural" da EF, do Esporte, na altura, era percebido como "diferenciação social positiva" (Bourdieu, 2012). Nesse ínterim, os Jogos Olímpicos, o efeito das "Teias de interdependência" (Elias, 1999), em tese, motivaram a implantação do projeto. Ponderações que se justificam à luz da Análise Crítica do Discurso, paralelamente com a imaginação sociológica de Norbert Elias, dado que enfatizam a importância de se criarem contextos (isto é, "Valências abertas") que favoreçam a percepção das disciplinas de cariz mais prático (Elias, 1939a; Elias, 1999; Fairclough \& Melo, 2012). Porém, de modo a problematizar, qual a situação do projeto sem o combustível dos megaeventos esportivos?

\footnotetext{
${ }^{7}$ A fim de informação: o Morro da Mineira é uma favela localizada na zona central do Rio de Janeiro.

${ }^{8}$ A fim de informação: grupos criminosos que controlam favelas do Rio de Janeiro.

${ }^{9}$ A fim de informação: o Intercolegial é uma das competições mais tradicionais do calendário esportivo escolar da cidade do Rio de Janeiro.
} 


\subsection{O presente da EM GEO Juan Antonio Samaranch: recorte 2018}

Antes de mais, é importante relatar que muita coisa mudou nesse espaço de tempo que compreende os sete primeiros anos da Escola Municipal GEO Juan Antonio Samaranch. No cenário sociopolítico, o Rio de Janeiro vem enfrentando intempéries de amplo espectro: a segunda maior metrópole do país esteve sob intervenção federal; o desemprego atingiu patamar recorde; a área da saúde sucumbe diante da malversação do dinheiro público; quatro dos últimos cinco governadores eleitos foram ou estão encarcerados; o presidente do Comitê Olímpico do Brasil (COB) e do Comitê Rio 2016 foi preso em mais uma fase da Operação Lava-Jato ${ }^{10}$.

No campo da segurança pública, a crise é um fator preocupante quando a pauta é o cotidiano da unidade escolar em estudo ${ }^{11}$. A cidade do Rio de Janeiro 'ostenta' uma série de aplicativos móveis que alertam para o risco de tiroteios, assaltos e/ou contingências relacionadas às violências. Os sentimentos de medo, de insegurança, com o findar dos megaeventos esportivos, atingiram patamares inaceitáveis. O número de policiais assassinados é assombroso. O percentual de mortos, de pessoas alvejadas por disparos de arma de fogo, se assemelha aos de países em guerra (IPEA, 2018).

Cenário de guerra:

- Mano, a UPP [Unidade de Polícia Pacificadora] acabou! A cada dia que passa esse lugar tá pior. - Cara, não tem um dia que a gente não vê alguém armado... um fuzil... uma troca de tiros. - A verdade é que o governo, a SME, construiu um forte... encheu de crianças... e esqueceu a gente aqui dentro: isso aqui é um forte... essa escola é um forte.... Verdade, colocaram a gente aqui dentro... no meio desse cenário de guerra... com milhões de problemas... milhões de coisas para resolver: se vira! - Mano, olha o nosso trabalho: nós ganhamos tudo... os alunos participam do campeonato carioca... do brasileiro... saem daqui para as melhores escolas do Rio de Janeiro... para escolas da elite carioca com bolsa atleta.... - Cara, na real, se não fosse por essas crianças... se eu não fosse tão apaixonado por isso aqui... eu já tinha jogado tudo isso pro alto! (Primeiro contato com os Treinadores do GEO. Un. Santa Teresa - Notas de campo, grifo nosso).

Teias de interdependência:

- Eu estava conversando com um dos treinadores, por esses dias, e ele falou uma coisa que é a pura verdade: essa escola nunca mais vai ser aquela escola da época das UPPs [Unidades de Polícia Pacificadora]. Ele tem razão. A realidade do entorno influencia diretamente no nosso trabalho; influencia diretamente no dia a dia da escola. Exemplo: semana passada, um dos nossos ex-alunos veio à escola de moto. Ele foi parado pelos policiais militares que falaram assim: avisa os caras lá em cima [os traficantes] que a gente [os policiais] não quer problema com eles. Ou seja, as UPPs acabaram; o Rio de Janeiro está entregue às moscas! (Treinador, GEO. Un. Santa Teresa - Notas de campo, grifo nosso).

Na esfera municipal da Educação, especificamente no domínio da Secretaria Municipal de Educação do Rio de Janeiro, a gratificação por conta das quarenta horas semanais de trabalho é coisa do passado; a bonificação ao corpo docente, ao corpo técnico-administrativo das unidades escolares que eventualmente batiam as metas de desempenho é algo inimaginável na atualidade; da mesma forma que, a título de contextualização, as viagens a Nova Iorque (Estados Unidos da América), uma espécie de prêmio aos professores de Matemática e Português, desapareceram do programa de incentivos da SME/RJ ${ }^{12}$.

\footnotetext{
${ }^{10}$ (Consult. 20/11/2018, disponível em https://vejario.abril.com.br/cidades/carlos-arthur-nuzman-e-preso-por-operacao-lava-jato/).

11 * “O que o luto da rede municipal do Rio diz sobre a violência que atinge as escolas. No período de um ano, 28,5\% das escolas da cidade do Rio de Janeiro perderam aulas por conta de tiroteios.".

(Consult. 29/11/2018, disponível em https://novaescola.org.br/conteudo/11902/o-que-o-luto-da-rede-municipal-do-rio-diz-sobre-a-violencia-que-atinge-asescolas).

12 (Consult. 20/11/2018, disponível em https://oglobo.globo.com/rio/fazenda-admite-que-prefeitura-do-rio-nao-tem-dinheiro-para-pagar-13-salario-de-servidor23142556).
} 
Apesar disso, a reboque da recessão, a camada privilegiada da sociedade precisou rever seus conceitos quanto à escola pública e as suas interfaces. Em nota divulgada no dia 25 de janeiro de 2018, a SME/RJ informou, na figura dos seus agentes, que nos anos anteriores recebera um número expressivo de alunos oriundos dos colégios particulares. Os dados, conforme consta no site da instituição, ainda são preliminares. Todavia, estima-se que a SME/RJ tenha acolhido desde 2017 (em suas 1.537 escolas) mais de 45 mil alunos provenientes da rede particular de ensino ${ }^{13}$.

No plano estadual da Educação, nomeadamente no âmbito da Secretaria de Estado de Educação do Rio de Janeiro (SEEDUC), a realidade é equivalente. Consequentemente, a procura por vagas no site da secretaria, nesse meio-tempo, aumentou exponencialmente. Do montante de inscrições para o ano letivo de 2018, cerca de 31 mil foram de estudantes oriundos da rede privada (colégios). De acordo com o Núcleo de Imprensa do Palácio Guanabara, a soma dos alunos que pretendem migrar da rede particular para a rede pública, representa aproximadamente $14 \%$ do número total de inscritos ${ }^{14}$.

Por influência disso, a EM GEO Juan Antonio Samaranch começou a acolher alunos descendentes das camadas privilegiadas. $\mathrm{O}$ efeito da crise, nesse sentido, resultou no reconhecimento da unidade escolar, visto que nos primeiros anos do projeto, o corpo discente era composto (em sua maioria) por crianças e jovens originárias de favelas ou comunidades circunvizinhas. Assim sendo, deve-se enfatizar que a unidade acolhe, através de processo seletivo, alunos na faixa etária de 10 a 15 anos. É uma instituição vocacionada para o esporte, e que no ano letivo de 2018 foi responsável pela escolarização de 560 alunos.

Nesse caso, é fundamental deixar claro que de fato muita coisa mudou nesse espaço de tempo que compreende os sete primeiros anos da EM GEO Juan Antonio Samaranch. A manutenção, boa parte dos consertos e reparos da primeira escola vocacionada para o esporte do Brasil, com o findar dos megaeventos esportivos, ficou a cargo da comunidade escolar. A remessa de material esportivo, que antes era expressiva, cessou. A oferta de ônibus, para o deslocamento dos alunos para as competições, minguou. A visitação dos políticos, dos atletas olímpicos, das celebridades, que num passado recente era constante, encerrou.

A Rede Globo de Televisão, citando caso análogo, deixou de televisionar o treino dos alunos. A gestão atual, diferentemente das anteriores, não possui a carta branca da SME/RJ. A requisição de professores, por exemplo, segue os trâmites burocráticos comuns da rede municipal de ensino. A manutenção, a conservação das áreas esportivas depende da capacidade de persuasão (do envolvimento) dos agentes diretivos junto à comunidade escolar. Pois é, a EM GEO Juan Antonio Samaranch deixou de ser a menina-dos-olhos dos homens públicos brasileiros (Reflexão do Pesquisador responsável - Notas de campo).

Realidade versus sentimento:

- O GEO piorou por causa da corrupção. Ou seja, o dinheiro que deveria vir para a escola não vem. Isso é uma pouca vergonha! (Discente, GEO. Un. Santa Teresa - Grupo focal). - As pessoas falam que o GEO piorou com a saída dos antigos diretores. Nada disso! O GEO não é mais o mesmo pelo que está acontecendo: falta de investimento, corte nos investimentos e tudo aquilo que todos nós já estamos cansados de ver nos jornais. Isso proporciona um sentimento que o GEO não é mais o mesmo. Mas o GEO, em minha opinião, em relação às outras escolas, ainda é uma escola superior! (Discente, GEO. Un. Santa Teresa - Grupo focal).

Redirecionando o imaginário coletivo:

${ }_{13}$ (Consult. 29/11/2018, disponível em http://prefeitura.rio/web/guest/exibeconteudo?id=7645305).

${ }_{14}$ (Consult. 29/11/2018, disponível em http://agenciabrasil.ebc.com.br/educacao/noticia/2017-12/quase-14-dos-alunos-das-escolas-privadas-tentam-migrar-para-redepublica). 
- Eu diria que hoje a gente está igual a todo mundo da rede municipal de ensino. Nos anos que antecederam os megaeventos esportivos, aí sim, a comunidade escolar teve muitos incentivos. Do ano passado pra cá as coisas começaram a decair. Eu acho que a gente consegue sobreviver, manter o padrão GEO, porque nós temos uma mentalidade de nunca desistir. Os professores, os profissionais dessa escola, têm um padrão profissional que não querem perder, a gente se exige isso. Então quando você assiste uma reunião que a gente chora, briga, quase sai na porrada, é porque a gente está percebendo que estamos perdendo muita coisa; muita coisa que é fundamental para o nosso trabalho e principalmente para o desenvolvimento dos nossos alunos! (Docente EF, GEO. Un. Santa Teresa Entrevista semiestruturada).

A teoria do foguete:

- O projeto, o GEO, é filho de pais riquíssimos, milionários. O GEO nasce no contexto do Brasil pré-grandes eventos, pré-copa, pré-olimpíada. O foguete, àquela altura, tinha que decolar: os recursos apareciam de todos os lados. Hoje a nossa realidade é outra. O GEO, o projeto, caiu pra adoção; está sendo criado por uma mãe solteira. Que seria, no caso, a CRE; a CRE com todas as suas dificuldades, pós-copa, pós-olimpíada, pós-Lava-Jato. Na verdade, hoje o foguete está nos braços dos professores: a gente é que carrega isso aqui nas costas. (Agente diretivo, GEO. Un. Santa Teresa - Entrevista semiestruturada).

Por todo o exposto, observa-se, em última análise, que o "capital simbólico" do Esporte, da Educação Física, antes compreendido como "diferenciação social positiva", perdeu espaço na agenda dos homens públicos brasileiros com o término dos megaeventos esportivos (Bourdieu, 2004; Bourdieu, 2001). Intrigante, não é? Ora, há quem duvide que o cenário seja este. É compreensível! Contudo, como não questionar o total abandono do Parque Olímpico ${ }^{15}$ ? Como não fazer objeção à medida que previa o fim da obrigatoriedade do conteúdo EF nas grades curriculares do Ensino Médio? Nesta esteira de pensamento, há fortes indícios que sugestionam que a unidade escolar em voga é apenas o apêndice desse eixo de tensões; o reflexo microssocial do "Negado" dos megaeventos esportivos (Trajan et al., 2013).

\section{Considerações Finais}

Nomeadamente, antes de voltar às atenções para as questões derradeiras, é importante ratificar ser utópica a intenção de ajuizar uma única escola como sendo o lugar da EF. Portanto, nota-se que tanto a EM GEO Juan Antonio Samaranch quanto as demais unidades escolares vocacionadas para o esporte da SME/RJ, cada uma, a seu modo e dentro de suas possibilidades, procura resguardar a legitimidade da EF, visto que o caráter legítimo da disciplina é previsto em Lei como meio de salvaguardar o exercício profissional do professor de EF, sobretudo a promoção prioritária do esporte educacional como elemento cultural e curricular já enraizado à Escola.

Relativamente aos Instrumentos de coleta de dados, os investigadores optaram por abdicar da análise documental como parte integrante dos procedimentos metodológicos, concentrando os esforços na leitura da paisagem social, mesmo tendo ciência de que tal decisão denotaria limitações quanto à investigação. Entretanto, nada que deponha contra a substância da pesquisa, dado que também é utópica a intenção de ajuizar uma única investigação como sendo uma fonte inesgotável de conhecimento, ponderação que enfatiza a análise sistemática dos documentos como uma das potenciais inquirições futuras, em virtude dos indícios sugestionarem o distanciamento entre os textos legais e a práxis da unidade escolar em destaque.

Nessa disposição, identifica-se que a unidade averiguada é uma escola que procura blindar suas práticas enquanto enjeita a anticultura e as forças motrizes que hodiernamente desestabilizam a formação integral dos alunos, principalmente

\footnotetext{
15 * "Parque Olímpico abandonado compromete legado da Rio 2016. Muito se falou sobre o legado esportivo da Copa do Mundo e dos Jogos Olímpicos. Já tinha sido assim quando do Pan-Americano de 2007, no Rio. O que se vê é a repetição dos fatos. Arenas em desuso ou mal aproveitadas e promessas que se esvaem com o tempo. Seis meses depois das Olimpíadas, as instalações construídas, definitivamente ou temporariamente, estão à espera de alguma competição ou intervenção.”.

(Consult. 28/11/2018, disponível em https://www.terra.com.br/esportes/jogos-olimpicos/2016/parque-olimpico-abandonado-compromete-legado-da-rio2016,78f0a36618d120bbd1197cae47234abbmnojabmk.html).
} 
daqueles cuja escola é o único espaço de aprendizagem pedagogicamente orientada. Consequentemente, diante disso, o papel da Escola Municipal GEO Juan Antonio Samaranch, do professor de Educação Física singularmente, é significativo quanto à educação (escolarização) pelo corpo. Todavia, não reflete a realidade sinistra da grande maioria das escolas da capital fluminense.

Em função disso, verifica-se que não se pode (deve) dissociar os fenômenos que cercam o currículo da SME/RJ dos fatos que subjugam o lugar da Educação Física na sociedade. Tal análise levou os investigadores a não atentarem somente para o discurso oficial, posto que a manifestação oficiosa tende a regular a incorporação dos conteúdos. Ainda assim, a inclusão efetiva da expressão cultural em estudo, vide a relevância do esporte no âmbito da unidade, está intimamente ligada à força relativa do professor de EF e intrinsecamente concatenada à eficácia desse profissional junto às estruturas de poder que delimitam e incrementam a relação indivíduo-sociedade (Elias, 1999).

Especificamente nesse caso, a subversão, a insubordinação do corpo docente da Escola Municipal GEO Juan Antonio Samaranch, particularmente dos professores de Educação Física, expõe a inconsistência das orientações curriculares da Secretaria Municipal de Educação do Rio de Janeiro ${ }^{16,17}$. Em outras palavras, se, por um lado, a subversão, a insubordinação do corpo docente não se limita às sugestões niveladas pela SME/RJ, por outro, em princípio, insinua a malversação do dinheiro público, posto que a falta de investimentos, quer seja na área acadêmica, quer seja na esfera esportiva, é prontamente superada pelo ímpeto da comunidade escolar, principalmente nos períodos de crise.

Consequentemente, por se tratar da primeira escola vocacionada para o esporte do Brasil, a unidade averiguada implementa suas práticas sob a premissa da corporalidade. Não é surpresa, então, que a tônica da Educação Física, do Esporte, da Cultura corporal de movimento, na ótica da Análise Crítica do Discurso (Fairclough \& Melo, 2012), seja apontada como a base de todas as etapas do processo ensino-aprendizagem, tendo como eixo norteador o conjunto de valores que sustentam a máxima do: "Aluno - Atleta - Cidadão". Ou seja, um currículo, uma perspectiva de Escola totalmente diferenciada das demais unidades escolares da Secretaria Municipal de Educação do Rio de Janeiro.

Por efeito disso, tendo em vista o paradigma anticultural que assola a escola em meio à contemporaneidade, a figura do professor atua na contramão dessa "configuração" (Elias, 1999), estando alinhado com os valores éticos (morais) que edificam a incumbência tradicional da Instituição Escola. Conclusivamente, o professor da unidade escolar em estudo, o professor de EF em particular, vai de encontro aos arbítrios da estrutura dominante (Bourdieu \& Passeron, 1978). Isto é, é contrário às engenharias que engendram práticas anticulturais. No entanto, o GEO Juan Antonio Samaranch ainda é uma exceção; não retrata, como reportado preliminarmente, o cenário caótico da maioria das escolas municipais do Rio de Janeiro.

\section{Referências}

Almeida, A. P. de. (2012). A escola perante o sedentarismo e a obesidade: Análise das políticas públicas escolares na cidade do Rio de Janeiro. Alex Almeida. Dissertação de doutoramento apresentada à Faculdade de Desporto da Universidade do Porto.

Alves, M. H. M., \& Evanson, P. (2013). Vivendo no fogo cruzado: moradores de favela, traficantes de droga e violência policial no Rio de Janeiro. São Paulo: Unesp.

\footnotetext{
${ }^{16}$ A interpretação do Professor-GEO: - A nota 6 é fictícia. A SME é muito permissiva em relação às notas, em relação à reprovação dos alunos. Aqui nós somos mais rigorosos e isso funciona. É claro que não podemos reprovar um aluno que tirou, por exemplo, 5,5. Mas, a nossa pressão, o nosso empenho em passar para os alunos que a nota mínima é 6, funciona. No último Ideb [Índice de Desenvolvimento da Educação Básica] alcançamos o patamar de segunda melhor escola da rede. Ou seja, as pessoas podem falar qualquer coisa dos professores dessa escola. Só não podem falar que não damos o nosso melhor! (Docente, GEO. Un. Santa Teresa - Grupo focal, grifo nosso).

${ }^{17}$ A interpretação do Aluno-GEO: - A minha antiga escola seguia as regras da SME, era uma escola normal, uma escola voltada para as apostilas. O GEO não cumpre as regras da SME. Regra da SME: trabalhe igual um louco e viva igual um burro. Regra do GEO: estude igual um louco e viva igual um rei, entendeu a diferença? (Discente, GEO. Un. Santa Teresa - Grupo focal). - Romualdo [nome fictício], poderia explicar a parte em que você fala: trabalhe igual um louco e viva igual um burro? (Pesquisador responsável - Grupo focal, grifo nosso). - Professor [Pesquisador responsável], o que ele quis dizer foi o seguinte: como as escolas da rede, da SME, não ensinam nada, são escolas voltadas para as apostilas, o futuro dos alunos é trabalhar igual um louco e viver igual um burro. Já o aluno do GEO, dessa escola, como estudou igual um louco, no futuro viverá igual um rei, entendeu? (Discente, GEO. Un. Santa Teresa Grupo focal, grifo nosso).
} 
Barbosa, C. L. de. A. (2011). Educação Física e Didática: Um diálogo possível e necessário. Vozes.

Barbosa, M. V. (2015). Estudo de caso de uma nova proposta educacional de escola integral vocacionada para o esporte.: Michelle Barbosa. Dissertação de mestrado apresentada à Faculdade Salgado de Oliveira.

Bourdieu, P., \& Passeron, J. (1978). A REPRODUÇÃO - Elementos para uma teoria do sistema de ensino. Editorial VEGA.

Bourdieu, P. (2007a). A Escola conservadora: as desigualdades frente à escola e à cultura. In P. Bourdieu. (Ed.), Escritos de educação (pp. 39-64). Rio de Janeiro: Vozes.

Bourdieu, P. (2007b). A distinção: crítica social do julgamento. Edusp; Zouk.

Bourdieu, P. (2012). O poder simbólico (16a ed.). Bertrand Brasil.

Elias, N. (1939a). O Processo civilizador. Volume 1: Uma história dos Costumes. Jorge Zahar.

Elias, N. (1939b). O Processo civilizador. Volume 2: Formação do Estado e Civilização. Jorge Zahar.

Elias, N. (1999). Introdução à sociologia. Edições 70.

Fairclough, N., \& Melo, I. (2012). Análise crítica do discurso como método em pesquisa social científica. Linha D’Água, 25(2), $307-329$.

Ferrari, C. E. R. de. A. (2014). Asfalto, favela e violência: o processo ensino-aprendizagem no cenário da educação física escolar - um estudo de caso. Niterói. Rio de Janeiro: Carlos Ferrari. Dissertação de mestrado apresentada à Faculdade Salgado de Oliveira.

Ferrari, C. E. R. de. A. (2020). O lugar da Educação Física na Escola Cultural. Estudo elaborado a partir da realidade de duas escolas sui generis do Porto e do Rio de Janeiro. F. Carlos Eduardo Rafael de Andrade. Tese de Doutoramento em Ciências do Desporto apresentada à Faculdade de Desporto da Universidade do Porto.

FGV. (2017). Educação em alvo: os efeitos da violência armada nas salas de aula. http://dapp.fgv.br/educacao-em-alvo-os-efeitos-da-violencia-armada-nassalas-de-aula/

Flick, U. (2004). Uma introdução à pesquisa qualitativa (2a ed.). Bookman.

Gardner, H. (1983). Estruturas da mente: A Teoria das Múltiplas Inteligências. Artes Médicas.

Gatti, B. A. (2005). Grupo focal na pesquisa em ciências sociais e humanas. Líber Livro.

IPEA. (2018). Atlas da violência. Fórum Brasileiro de Segurança http://www.ipea.gov.br/portal/images/stories/PDFs/relatorio_institucional/180604_atlas_da_violencia_2018.pdf

Kunz, E. (1995). A relação teoria/prática no ensino/pesquisa da educação física. Motrivivência/Florianópolis, 7(8), $46-54$.

Mattos, D. C. de. (2014). Ginásio Experimental Olímpico: a transformação de uma ideia em um projeto de sucesso. In C. A. F. da. Silva. (Ed.), Aluno - Atleta - Cidadão. Estudos no Ginásio Experimental Olímpico (pp. 107-138). HP Comunicação Editora.

Minayo, M. C. de. S. (1994). Ciência, técnica e arte: O desafio da pesquisa social. In M. C. de. S. Minayo. (Ed.), Pesquisa social: Teoria, método e criatividade (pp. 9-30). Vozes.

Negrine, A. (1999). Instrumentos de coleta de informações na pesquisa qualitativa. In V. M. Neto., \& A. N. S. Triviños. (Eds.), A pesquisa qualitativa na educação física (pp. 61-94). Universidade/UFRGS/Sulina.

Pereira, A. L. (2013). Para uma pesquisa no terreno em ciências do desporto. In I. Mesquita., \& A. Graça. (Eds.), Investigação qualitativa em Desporto (Vol. 1, pp. 97-119). FADEUP.

Santos, L. C., \& Silva, C. A. F. da. (2020). Consequências da violência armada carioca para as aulas de educação física. 26, e26036, 1-14.

Silva, C. A. F. da. (2013). Mídia, legados e olimpíadas no Brasil. In C. Costa., \& C. Silva. (Eds.), Favelasport: Estudos sobre o fenômeno esportivo em comunidades do Rio de Janeiro (pp. 68-93). SUAM.

Silva, C. A. F. da. (2014). Aspectos Etnometodológicos e Ações Cotidianas no GEO. In C. A. F. da. Silva. (Ed.), Aluno - Atleta - Cidadão. Estudos no Ginásio Experimental Olímpico (pp. 39-58). HP Comunicação Editora.

Silva, J. E. da., \& Silva, L. F. da. (2014). Representações sobre o aluno-atleta-cidadão: um estudo no ginásio experimental olímpico. In C. A. F. da. Silva. (Ed.), Aluno - Atleta - Cidadão. Estudos no Ginásio Experimental Olímpico (pp. 11-38). HP Comunicação Editora.

Silva, L. F. da. (2017). Percepções dos alunos e professores de Educação Física do GEO - Juan Antonio Samaranch diante das aulas de Educação Física curricular. Niterói. Rio de Janeiro: Leonardo Silva. Dissertação de mestrado apresentada à Faculdade Salgado de Oliveira.

Trajan, A. de. A., Ferrari, C. E. R. de. A., \& Silva, C. A. F. da. (2013). Legado ou Negado? Primeiros Impactos dos Jogos Olímpicos de 2016: Desrespeito ao Direito à Moradia na Vila do Autódromo. In C. Costa., \& C. Silva. (Eds.), Favelasport: Estudos sobre o fenômeno esportivo em comunidades do Rio de Janeiro (pp. 184-197). SUAM.

Triviños, A. N. S. (1987). Introdução à pesquisa em ciências sociais: a pesquisa qualitativa em educação. Atlas.

Vago, T. M. O. (1996). O “esporte na escola" e o "esporte da escola": da negação radical para uma relação de tensão permanente. Um diálogo com Valter Bracht. Revista Movimento, 3(5), 4-17. 
Research, Society and Development, v. 10, n. 16, e540101624019, 2021

(CC BY 4.0) | ISSN 2525-3409 | DOI: http://dx.doi.org/10.33448/rsd-v10i16.24019

Valladão, L. F., Osborne, R., \& Dutra, M. B. (2013). Infraestrutura da educação física na rede municipal de Niterói. In R. Osborne., C. A. F. da. Silva., \& R. F. dos. Santos. (Eds.), Complexidade da educação física escolar: questões atuais e desafios para o futuro (pp. 11-18). Lamparina editora.

Yin, R. K. (2005). Estudo de caso: planejamento e métodos (3a ed.). BooKman.

Zeferino, J. L. B. (2014). Relatos. In C. A. F. da. Silva. (Ed.), Aluno - Atleta - Cidadão. Estudos no Ginásio Experimental Olímpico (pp. 165-178). HP Comunicação Editora. 